\title{
When should a mechanical tricuspid valve replacement be considered?
}

\author{
Sameh M. Said, MD, ${ }^{\mathrm{a}}$ Harold M. Burkhart, MD, ${ }^{\mathrm{a}}$ Hartzell V. Schaff, MD, ${ }^{\mathrm{a}}$ Jonathan N. Johnson, MD, \\ Heidi M. Connolly, MD, ${ }^{\mathrm{c}}$ and Joseph A. Dearani, $\mathrm{MD}^{\mathrm{a}}$
}

Background: Isolated mechanical tricuspid valve replacement (mTVR) is uncommon, early mortality is reported to be high, and little is known regarding the long-term outcome. We sought to evaluate the long-term outcome of mTVR.

\begin{abstract}
Methods: From 1980 to 2007, isolated mTVR was performed in 64 patients (33 men) at our institution; the median age was 45.5 years (6-71 years). There were 2192 tricuspid valve (TV) repairs and 137 isolated bioprosthetic TV replacements during the same time interval. Valve dysfunction was caused by congenital TV abnormality in 45 patients $(70 \%)$, carcinoid heart disease in $13(20 \%)$, traumatic TV regurgitation in $3(5 \%)$, and other reason in $3(5 \%)$. Twenty-three patients $(36 \%)$ had at least 1 previous cardiac procedure (TV repair in 8 and bioprosthetic TV replacement in 7).
\end{abstract}

Results: Mechanical prostheses used included Starr-Edwards (before 1993) in 36 patients (56\%) and bileaflet prostheses in $28(44 \%)$. Concomitant procedures included atrial septal defect closure in $28(44 \%)$, arrhythmia surgery in $11(17 \%)$, and pulmonary valvectomy for carcinoid disease in 10 patients $(16 \%)$. Early mortality occurred in 5 patients $(7.8 \%)$. Early morbidity included a permanent pacemaker in $9(14 \%)$ and reexploration for bleeding in 2 patients (3\%). Mean follow-up was 6 years (maximum 22.4 years). Five- and 10-year survival was $65 \%$ and $58 \%$, respectively. There was no valve-related mortality. Late morbidity included valve thrombosis in 5 patients (8\%); 3 were managed nonoperatively and 2 underwent TV rereplacement.

Conclusions: Isolated mTVR still leads to increased early mortality. A mechanical valve can be considered in select situations when anticoagulation is necessary and in the presence of good right ventricular function. (J Thorac Cardiovasc Surg 2014;148:603-8)

Tricuspid valve replacement (TVR) is rarely performed compared with tricuspid valve (TV) repair. TV repair is usually the procedure of choice, and, when not possible, the decision has to be made on which type of prosthetic valve to use. When TVR is performed, it is usually as a combined procedure with other valve replacements. ${ }^{1}$ TVR is associated with high early mortality ${ }^{2}$ and little is known regarding long-term outcomes.

\section{PATIENTS AND METHODS}

The current study was approved by the Mayo Foundation Institutional Review Board. We retrospectively reviewed 64 patients who underwent isolated mechanical TVR (mTVR) at the Mayo Clinic, Rochester, Minnesota, between 1980 and 2007. During this period, there were 2192 TV repairs and 137 isolated bioprosthetic TVRs. TV repair was preferred if possible.

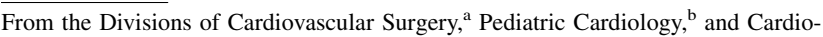
vascular Diseases, ${ }^{\mathrm{c}}$ Mayo Clinic, Rochester, Minn.

Disclosures: Authors have nothing to disclose with regard to commercial support.

Received for publication June 15, 2013; revisions received Aug 25, 2013; accepted

for publication Sept 12, 2013; available ahead of print Nov 6, 2013.

Address for reprints: Harold M. Burkhart, MD, Division of Cardiovascular Surgery,

Mayo Clinic, 200 First St. SW, Rochester, MN 55905 (E-mail: burkhart.harold@

mayo.edu).

$0022-5223 / \$ 36.00$

Copyright (c) 2014 by The American Association for Thoracic Surgery

http://dx.doi.org/10.1016/j.jtcvs.2013.09.043
}

Among the 64 patients who underwent mTVR, there were 33 men (52\%), ranging in age from 6 to 71 years (mean age, $43.2 \pm 15$ years). Congestive heart failure was the presenting symptom in 27 patients $(42.2 \%)$. Moderate-severe right ventricular dysfunction was demonstrated on preoperative echocardiography in 20 patients (31\%).

TVR was performed for isolated severe regurgitation in 53 patients $(83 \%)$; severe TV stenosis was the main indication for TVR in 3 patients $(4.7 \%)$. Severe TV regurgitation caused by Ebstein malformation of the TV was found in 45 patients $(70 \%)$, carcinoid heart disease in $13(20 \%)$, and a double outlet right ventricle in 1 patient $(1.6 \%)$. Two patients $(3 \%)$ had distortion of the TV by the prosthetic patch that was used for a previous ventricular septal defect closure, and 1 patient $(1.6 \%)$ had moderate-severe TV regurgitation as a result of radiationinduced heart disease. One patient had lupus anticoagulant syndrome causing TV disease and requiring life-long anticoagulation.

Eight patients $(12 \%)$ had previous TV repair; 5 patients $(8 \%)$ had 1 previous TVR and 2 patients $(3 \%)$ had 2 previous TVRs. Mechanical prostheses used were Starr-Edwards (Edwards Lifesciences, Irvine, Calif) in 36 patients (56\%; all before 1993), St Jude Medical (St Jude Medical, Inc, St Paul, Minn) bileaflet in $15(24 \%)$, and CarboMedics (Sulzer Carbomedics, Inc, Austin, Tex (division of Sulzer Medica) bileaflet in $13(20 \%)$ patients.

Concomitant procedures with TVR (Table 1) were closure of an atrial septal defect in 28 patients (44\%), arrhythmia surgery in $11(17 \%)$, pulmonary valvectomy for carcinoid heart valve disease in $10(16 \%)$, pulmonary valvotomy in $1(1.6 \%)$, repair of a ruptured sinus of Valsalva aneurysm in $1(1.6 \%)$, pericardiectomy in $1(1.6 \%)$, and coronary artery bypass grafting in $1(1.6 \%)$. Standard median sternotomy was the approach in 63 patients $(98 \%) ; 1$ TVR $(1.6 \%)$ was performed through a right thoracotomy. TVR was performed without aortic crossclamp in 7 patients $(11 \%)$. Warfarin was used for postoperative anticoagulation in all patients. 


\section{Abbreviations and Acronyms \\ INR = international normalized ratio \\ mTVR $=$ mechanical tricuspid valve replacement \\ $\mathrm{TV}=$ tricuspid valve \\ TVR $=$ tricuspid valve replacement}

patients $(3 \%)$ who required TV rereplacements for thrombosed prostheses.

There were no episodes of structural valve deterioration or prosthetic valve endocarditis reported during the follow-up period. Freedom from valve-related thrombosis at 1,5 , and 10 years was $97.3 \%, 87 \%$, and $87 \%$, respectively (Figure 4, A). Freedom from valve-related thrombosis was higher in the St Jude Medical and CarboMedics groups than the Starr-Edwards group at 1 year (100\% vs $95.2 \%$, respectively), but at 5 years, it was higher in the St Jude Medical and Starr-Edwards groups compared with the CarboMedics group $(100 \%, 95.2 \%$ vs $37.5 \%$, respectively) (Figure 4, B). Valve thrombosis occurred in 5 patients $(8 \%) ; 4$ of them had a therapeutic international normalized ratio (INR), at least moderate right ventricular dysfunction, and a dilated right ventricle. Valve thrombosis occurred despite adequate anticoagulation and a therapeutic INR at the time of identification. Two patients responded to thrombolytic therapy only and 2 required TV rereplacement. For the last patient, anticoagulation had to be held because of recent spine surgery and valve thrombosis responded to thrombolytic therapy after a failed attempt at percutaneous catheter balloon thrombectomy (Figure 5, $A$ and $B$ ); the patient did not require reoperation. No anticoagulation-related bleeding occurred during late follow-up.

\section{DISCUSSION}

TV repair is the technique preferred by many surgeons for treating moderate to severe TV regurgitation. TVR, despite becoming less attractive option in recent years, 3,4 still has a role in those patients who are not suitable for repair. A previous study from our institution ${ }^{5}$ indicated that adverse outcomes with TVR are related to the preoperative status; however, a better outcome may be achieved if the patient undergoes surgery before the onset of advanced right heart failure. From 1980 to 2007, we have performed 2192 tricuspid repairs and 201 TVRs, which includes the cohort of 64 patients in this study who underwent isolated mTVR.

The prosthesis of choice for TVR is still a matter of debate, ${ }^{6}$ and the concern about replacing the TV with a

TABLE 1. Concomitant procedures

\begin{tabular}{lcc}
\hline \multicolumn{1}{c}{ Procedure } & $\begin{array}{c}\text { Number } \\
\text { of patients }\end{array}$ & Percentage (\%) \\
\hline Atrial septal defect closure & 28 & 44 \\
Arrhythmias surgery & 11 & 17 \\
Pulmonary valvectomy & 10 & 16 \\
Pulmonary valvotomy & 1 & 1.6 \\
Repair of ruptured sinus of & 1 & 1.6 \\
$\quad$ Valsalva aneurysm & & 1.6 \\
Pericardiectomy & 1 & 1.6 \\
Coronary artery bypass graft & 1 & \\
\hline
\end{tabular}



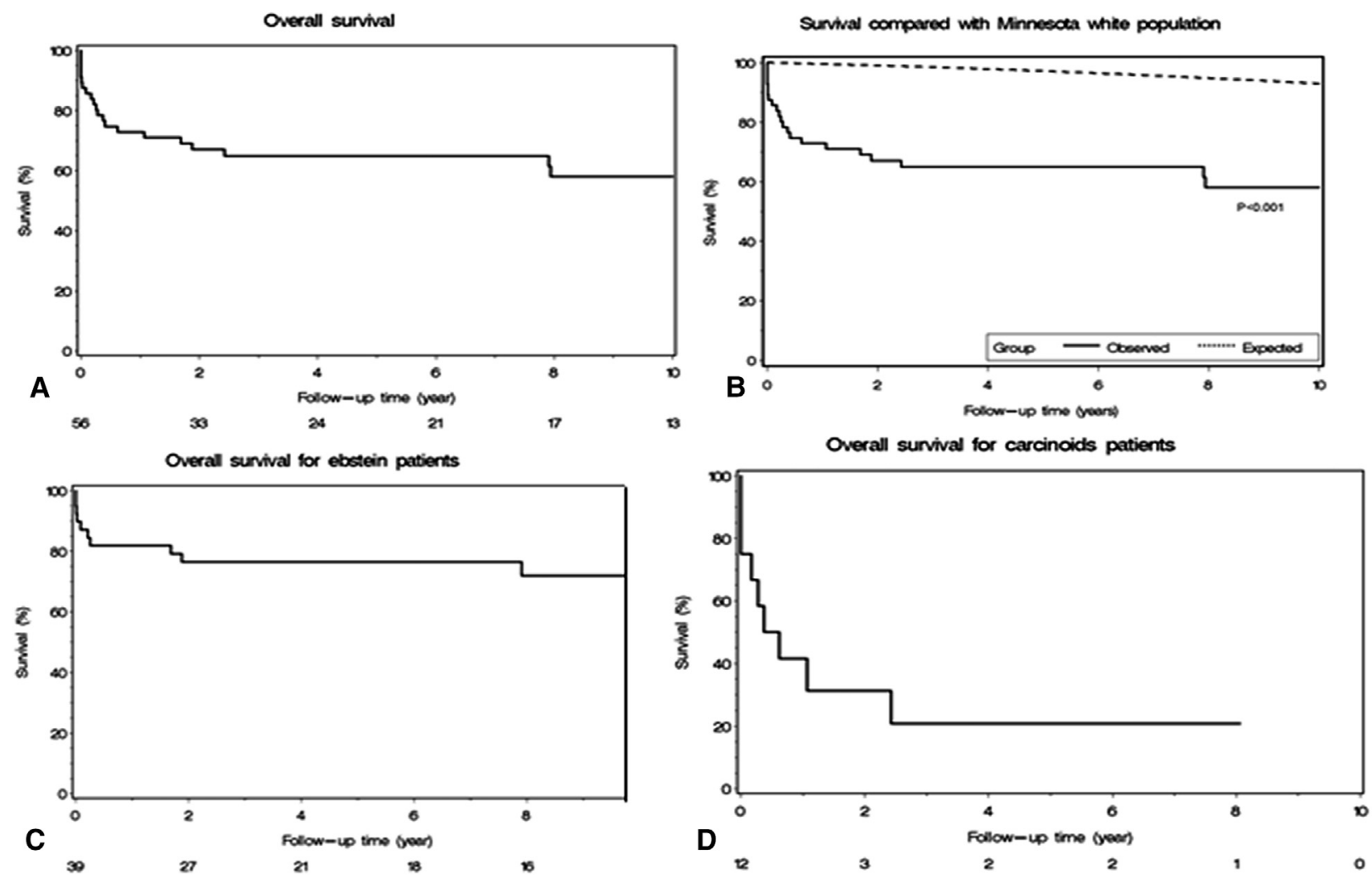

FIGURE 1. Survival curves: A, overall survival; B, survival of those who underwent isolated TVR compared with the white population of Minnesota; $\mathrm{C}$, overall survival of patients with Ebstein anomaly; D, overall survival of those with carcinoid heart disease.

mechanical prosthesis relates to the increased risk of valve thrombosis as well as valve dysfunction related to pannus formation as seen in previous studies. ${ }^{7}$ Valve selection should be based on discussion with the patient, paying special attention to the patient's lifestyle, the need for life-long warfarin therapy, and right ventricular function. In the current era, percutaneous valve technology has increased the likelihood of tissue TVR use, recognizing

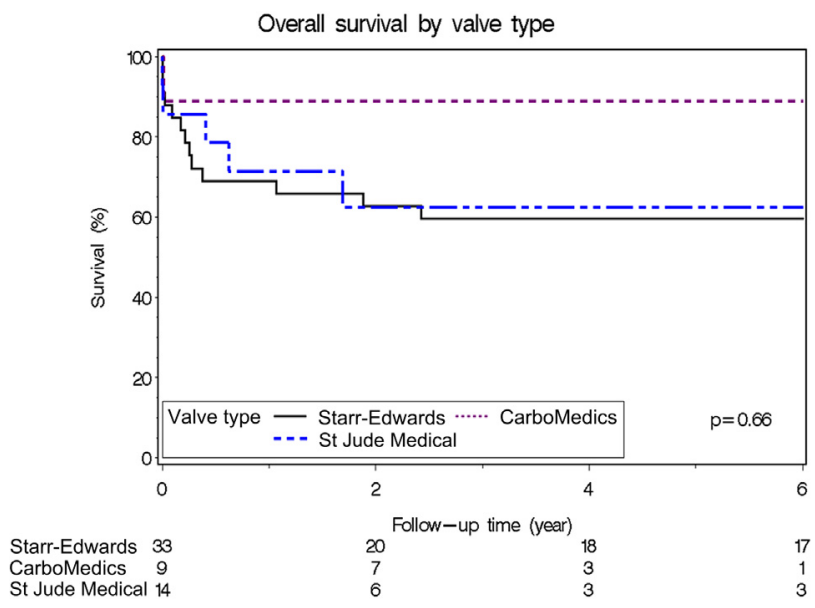

FIGURE 2. Overall survival according to the type of the prosthesis. percutaneous replacement as a management option in those with degeneration.

The question about the type of the prosthesis in the TV position was asked by Van Nooten and colleagues ${ }^{8}$ in their series of 146 TVRs, which included 69 bioprostheses and 77 mechanical prostheses. Their hospital mortality was

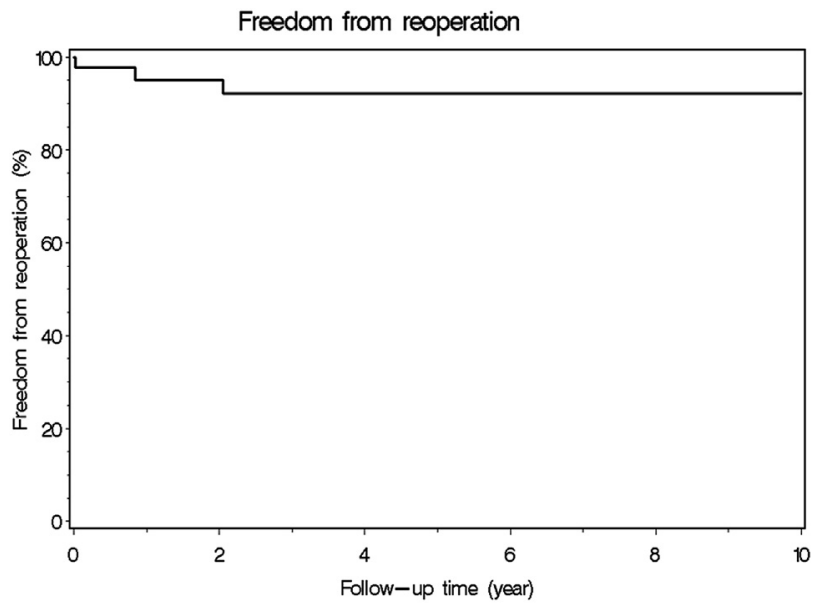

$\begin{array}{llllll}50 & 32 & 22 & 19 & 15 & 11\end{array}$

FIGURE 3. Freedom from reoperation at 1,5 , and 10 years was $95.1 \%$ $92.1 \%$, and $92.1 \%$, respectively. 


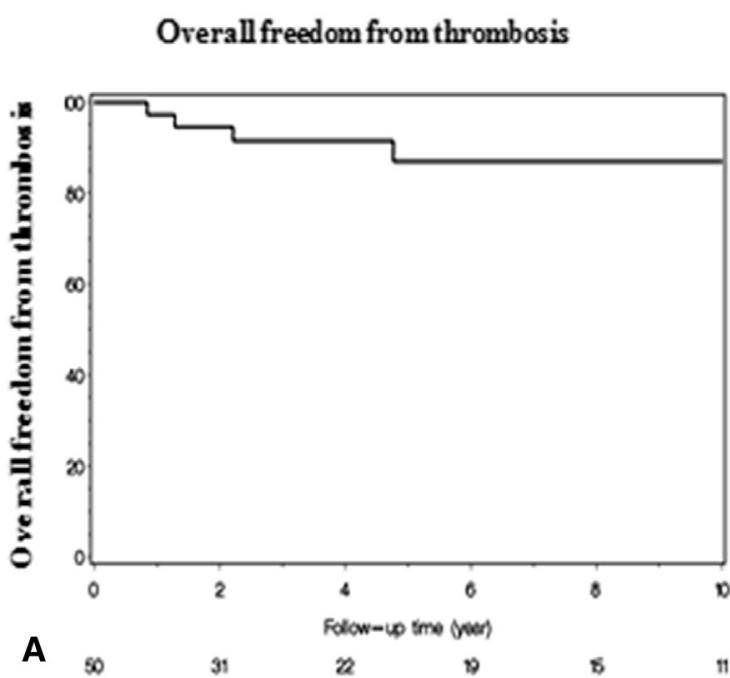

A
91
8
22
Freedom from thrombosis by valve type

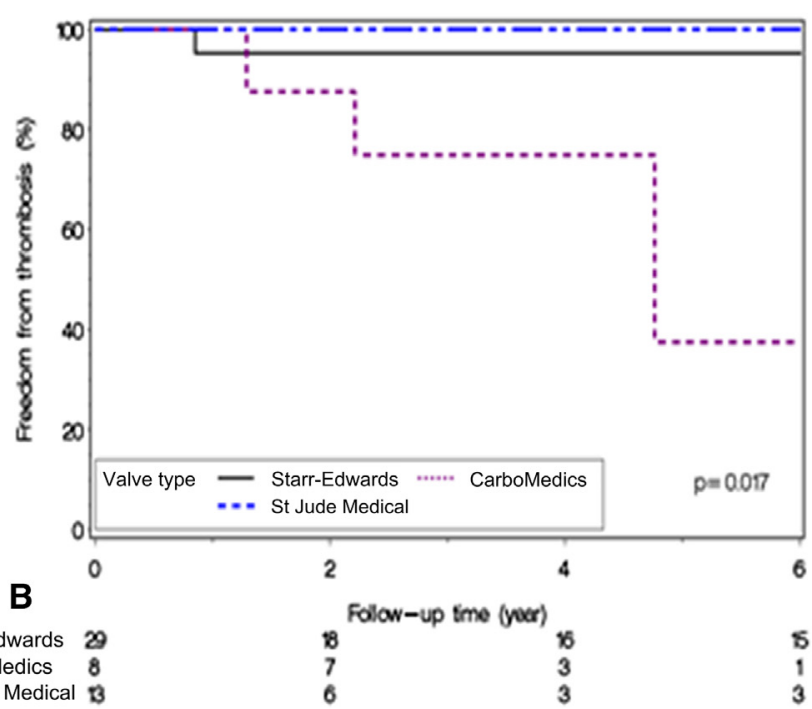

FIGURE 4. Freedom from prosthetic mechanical thrombosis: A, overall; and B, based on the type of prosthesis.

$16.1 \%$. The investigators concluded that the outcome of TVR is influenced by preoperative and perioperative variables such as preoperative functional class, hepatomegaly, ascites, icterus, and increased cardiothoracic ratio. They indicated their preference for a large-size bioprosthesis in view of its initial good durability and low-risk of valve-related events. However, in those with good life expectancy, an acceptable alternative is a bileaflet mechanical prosthesis.

Historically, there has been increased mortality with TVR compared with other types of valve replacement surgery. The early mortality in our patients was $9.4 \%$, which was mainly in the early years of the series (1980-1994), compared with early mortality of $0 \%$ for the latter years (1995-2007). This compares favorably with other series reported.

Mangoni and colleagues ${ }^{9}$ reported the outcome of isolated TVR in 15 consecutive patients, $20 \%$ of whom died within 30 days after surgery and $40 \%$ died within 3 months. The study by Filsoufi and colleagues ${ }^{10}$ reported on 81 patients (mean age, 61 years), including 25 patients with isolated TVR; the early mortality in this series was $22 \%$ and 47 patients had undergone TVR with a mechanical prostheses. The investigators identified the following as risk factors for mortality: urgency of the operation, age more than 50 years, functional tricuspid regurgitation, and pulmonary hypertension. In the series reported by Tokunaga and colleagues, ${ }^{11}$ there were 31 cases

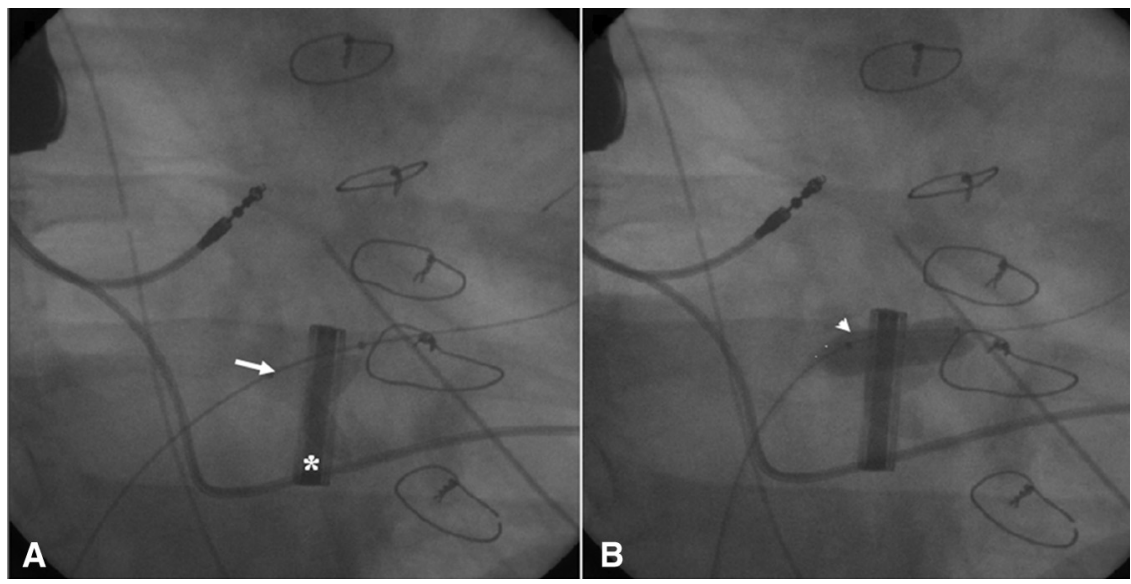

FIGURE 5. A and B, Cardiac catheterization images showing the technique of percutaneous balloon valvuloplasty with thrombectomy for a thrombosed mechanical tricuspid valve $(*)$. This procedure was performed in a patient who underwent spine surgery and his anticoagulation had to be held perioperatively, which resulted in thrombosis of the tricuspid valve prosthesis. A, White arrow indicates the catheter extending across the mechanical tricuspid valve (*); B, white arrowhead indicates balloon thrombectomy. 
of isolated TVR including only 4 patients who had mechanical prostheses; the hospital mortality was $6.5 \%$.

The largest series was reported by Ratnatunga and colleagues. ${ }^{12}$ They reported on their experience from the United Kingdom Heart Valve Registry comparing midterm outcomes between mechanical and biological prostheses in the TV position. A total of 425 patients underwent TVR; 225 patients $(52.9 \%)$ received biological prostheses and 200 received mechanical prostheses. The early mortality in this study was $17.3 \% ; 1-, 5-$, and 10 -year survival rates were $72.2 \%, 59.9 \%$, and $42.9 \%$, respectively. Predictors of overall survival included the year of the operation, age, and the number of valves implanted. Early mortality, although not statistically significant, was higher with the biological valves compared with the mechanical valves $(18.8 \%$ vs $15.6 \%)$. Survival rates at 1,5 , and 10 years were $70.5 \%, 61.5 \%$, and $47.7 \%$ for biological valves and $74.0 \%, 57.9 \%$, and $33.9 \%$ for mechanical valves. In the study reported by Chang and colleagues, ${ }^{13}$ the long-term outcomes of biological and mechanical prostheses were similar in 138 TVRs (35 biological, 103 mechanical) performed in 125 patients. Early mortality in that study was $17.6 \%$ and late mortality was $10.4 \%$. The surgical mortality in that study for biological valves was higher than for mechanical valves, although this was not significant. The investigators identified 11 episodes of thromboembolism in the mechanical group with freedom from thromboembolism at 5 and 10 years of $90.2 \pm 0.6 \%$ and $87.8 \pm 0.7 \%$, respectively.

Valve-related thrombosis at 1,5 , and 10 years in this study was $97.3 \%, 87 \%$, and $87 \%$, respectively, and it was significantly higher for the Starr-Edwards and St Jude Medical bileaflet prosthesis. In our 64 cases of mTVR, there were only 5 cases of valve thrombosis more than a year after valve replacement. Three of these patients had moderate or greater right ventricular systolic dysfunction. All patients reported therapeutic anticoagulation, and levels were in the appropriate range at the time of TVR thrombosis identification.

The risk of mTVR thrombosis was reported to be high in the early literature, varying between $4 \%$ and $20 \% .{ }^{14}$ This seems to be related to a reduced flow rate and lower pressure on the right side of the heart. ${ }^{15}$ The risk of TVR thrombosis seems to increase in the presence of right ventricular dysfunction, even in the presence of adequate anticoagulation, as was found in 3 of our patients in this series. Anticoagulation regimens have also changed over time, ${ }^{16}$ and in the current era, anticoagulant and antiplatelet agents are recommended for all patients with mechanical prostheses. ${ }^{17}$

We have noticed a lower thrombosis rate with the Starr-Edwards prosthesis and 1 explanation is the presence of a larger washing jet in this valve compared with other mechanical prostheses. That may be of value in the tricuspid position where the risk of mechanical thrombosis is higher compared with left-sided prostheses. The difference between CarboMedics and St Jude Medical valves is not clear. However, the same observation has been reported before in the aortic position by Kandemir and colleagues. ${ }^{18}$ The investigators reviewed the long-term results between $\mathrm{St}$ Jude Medical and CarboMedics mechanical heart valves in the aortic position in 174 patients. The freedom from thromboembolism was $87.7 \%$ for the St Jude Medical group versus $83 \%$ for the CarboMedics group. This was not statistically significant and the investigators attributed the difference to patient-specific characteristics and the method of anticoagulation. Others have noticed a higher thrombosis rate for CarboMedics valves in the mitral position as well. ${ }^{19}$ Rosengart and colleagues ${ }^{19}$ evaluated 245 consecutive patients who underwent mechanical valve replacement. There were 5 thrombosed valves in the CarboMedics group and none in the St Jude Medical group $(P=.04)$, and all thrombosed valves were in the mitral position. The investigators explained that some of the design features of the CarboMedics valve could enhance thromboembolic potentials; for example, the biocompatible sewing ring may encourage pannus formation and a valve opening profile may affect washout of stagnant flow areas where thrombus might form.

The use of bileaflet, especially St Jude Medical, prostheses has been associated with a low rate of thrombosis (freedom from thromboembolism was $92.6 \% \pm 6.9 \%$ ). ${ }^{20}$ The high rate of mechanical valve thrombosis reported previously was mainly in the early era of caged ball and tilting disc prostheses, ${ }^{21}$ and before aspirin therapy was routinely recommended for patients with a mechanical valve on warfarin.

Thrombosed mechanical TVRs can occasionally be salvaged by thrombolysis, however reoperation may be required in the presence of a large clot burden, marked prosthetic dysfunction, or contraindications to lytic therapy.

Five thrombosed mechanical prostheses were identified in our series. Three patients underwent successful thrombolytic therapy, including 1 patient after failed percutaneous thrombectomy; reoperation was performed in the other 2. The optimal way to manage thrombosed TVR remains controversial.

Thrombolytic therapy was first reported in 1971 by Luluaga and colleagues ${ }^{22}$ who used streptokinase to treat thrombosed Starr-Edwards TV prostheses. This approach has been associated with lower morbidity and mortality and is usually the recommended first step for thrombosed right-sided prostheses. ${ }^{23}$ Repeated thrombolysis was described in a 49-year-old woman with Ebstein anomaly who was treated with mTVR. She had 7 episodes of prosthetic thrombosis and all were managed with thrombolysis; she continued to be symptom free for 5 years after her last thrombotic event. ${ }^{24}$ In addition, in our study, no patient had any valve-related mortality or structural valve failure that required reoperation. 
Evaluation of right ventricular function is critical when TVR is considered. In the meantime, its complex geometry makes this evaluation a challenge. In our study, echocardiography was the only available method of evaluation, especially in the early era; however, magnetic resonance imaging is now used more frequently to evaluate right ventricular function preoperatively. The following are some of the proposed markers of right ventricular dysfunction: right ventricular ejection fraction, the presence of right ventricular dilatation, tricuspid annular velocity or excursion, right ventricular index of myocardial performance, TV regurgitation, and pressure-volume or pressure-area loops. ${ }^{25}$

In conclusion, TVR with a mechanical prosthesis still has its place and indications. The long-term outcome is satisfactory, with good durability and excellent freedom from reoperation. Based on our experience, we recommend considering use of a mechanical valve in the tricuspid position in patients who require warfarin anticoagulation, those with good right ventricular function, and less than moderate right ventricular dilatation. Our preference is a lowprofile bileaflet mechanical prosthesis. To achieve a good surgical outcome, patients may need to be referred earlier to surgery before the development of frank end-stage right ventricular dysfunction with associated right heart failure.

\section{References}

1. Garatti A, Nano G, Bruschi G, Canziani A, Colombo T, Frigiola A, et al. Twenty-five year outcomes of tricuspid valve replacement comparing mechanical and biologic prostheses. Ann Thorac Surg. 2012;93:1146-53.

2. Carrier M, Hebert Y, Pellerin M, Bouchard D, Perrault LP, Cartier R, et al. Tricuspid valve replacement: an analysis of 25 years of experience at a single center. Ann Thorac Surg. 2003;75:47-50.

3. Kaul TK, Mercer JL. Tricuspid valve replacement: factors influencing early and late mortality. J Thorac Cardiovasc Surg. 1990;38:229-35.

4. McGrath LB, Chen C, Bailey BM, Fernandez J, Laub GW, Adkins MS. Early and late phase events following bioprosthetic tricuspid valve replacement. J Cardiac Surg. 1992; 7:245-53.

5. Topilsky Y, Khanna AD, Oh JK, Nishimura RA, Enriquez-Sarano M, Jeon YB, et al. Preoperative factors associated with adverse outcome after tricuspid valve replacement. Circulation. 2011;123:1929-39.

6. Rizzoli G, Vendramin I, Nesseris G, Bottio T, Guglielmi C, Schiavon L. Biological or mechanical prostheses in tricuspid position? A meta-analysis of intra-institutional results. Ann Thorac Surg. 2004;77:1607-14.

7. Hwang HY, Kim KH, Kim KB, Ahn H. Mechanical tricuspid valve replacement is not superior in patients younger than 65 years who need long-term anticoagulation. Ann Thorac Surg. 2012;93:1154-60.

8. Van Nooten GJ, Caes FL, Francois KJ, Taeymans Y, Primo G, Wellens F, et al. The valve choice in tricuspid valve replacement: 25 years of experience. Eur J Cardiothorac Surg. 1995;9:441-7.

9. Mangoni AA, DiSalvo TG, Vlahakes GJ, Polanczyk CA, Fifer MA. Outcome following isolated tricuspid valve replacement. Eur J Cardiothorac Surg. 2001;19:68-73.
10. Filsoufi F, Anyanwu AC, Salzberg SP, Frankel T, Cohn LH, Adams DH. Long-term outcomes of tricuspid valve replacement in the current era. Ann Thorac Surg. 2005;80:845-50.

11. Tokunaga S, Masuda M, Shiose A, Tomita Y, Morita S, Tominaga R. Long-term results of isolated tricuspid valve replacement. Asian Cardiovasc Thorac Ann. 2008; $16: 25-8$

12. Ratnatunga CP, Edwards MB, Dore CJ, Taylor KM. Tricuspid valve replacement: UK Heart Valve Registry mid-term results comparing mechanical and biological prostheses. Ann Thorac Surg. 1998;66:1940-7.

13. Chang BC, Lim SH, Yi G, Hong YS, Lee S, Yoo KJ, et al. Long-term clinical results of tricuspid valve replacement. Ann Thorac Surg. 2006;81: 1317-24.

14. Lengyel M, Horstkotte D, Voller H, Mistiaen WP. Working group infection, thrombosis, embolism, and bleeding of the society for heart valve disease. Recommendations for the management of prosthetic valve thrombosis. J Heart Valve Dis. 2005; 14:567-75.

15. Thorburn CW, Morgan JJ, Shanahan MX, Chang VP. Long-term results of tricuspid valve replacement and the problem of prosthetic valve thrombosis. Am J Cardiol. 1983;51:1128-32.

16. Bonow RO, Carabello BA, Kanu C, de Leon AC Jr, Faxon DP, Freed MD, et al. ACC/AHA 2006 guidelines for the management of patients with valvular heart disease: a report of the American College of Cardiology/American Heart Association Task Force on Practice Guidelines (writing committee to revise the 1998 Guidelines for the Management of Patients With Valvular Heart Disease): developed in collaboration with the Society of Cardiovascular Anesthesiologists: endorsed by the Society for Cardiovascular Angiography and Interventions and the Society of Thoracic Surgeons. Circulation. 2006; 114:e84-231.

17. Bonow RO, Carabello BA, Chatterjee K, de Leon AC Jr, Faxon DP, Freed MD, et al. 2008 focused update incorporated into the ACC/AHA 2006 guidelines for the management of patients with valvular heart disease: a report of the American College of Cardiology/American Heart Association Task Force on Practice Guidelines (Writing Committee to revise the 1998 Guidelines for the Management of Patients with Valvular Heart Disease). Endorsed by the Society of Cardiovascular Anesthesiologists, Society for Cardiovascular Angiography and Interventions, and Society of Thoracic Surgeons. J Am Coll Cardiol. 2008; 52:e1-142.

18. Kandemir O, Tokmakoglu H, Yildiz U, Tezcaner T, Yorgancioglu AC, Gunay L, et al. St. Jude Medical and CarboMedics mechanical heart valves in the aortic position: comparison of long-term results. Tex Heart Inst J. 2006;33:154-9.

19. Rosengart TK, O'Hara M, Lang SJ, Ko W, Altorki N, Krieger KH, et al. Outcome analysis of 245 CarboMedics and St. Jude valves implanted at the same institution. Ann Thorac Surg. 1998;66:1684-91.

20. Kaplan M, Kut MS, Demitras MM, Cimen S, Ozler A. Prosthetic replacement of tricuspid valve: bioprostheses or mechanical. Ann Thorac Surg. 2002;73: 467-73.

21. Kao CL, Lu MS, Chang JP, Yang TY, Cheng HW. Thrombotic obstruction of a mechanical prosthetic valve in tricuspid position. Tex Heart Inst J. 2009;36: 261-3.

22. Luluaga IT, Carrera D, D’Oliveira J, Cantaluppi CG, Santin H, Molteni L, et al. Successful thrombolytic therapy after acute tricuspid valve obstruction. Lancet. 1971:1:1067-8.

23. Alpert JS. The thrombosed prosthetic valve: current recommendations based on evidence from the literature. J Am Coll Cardiol. 2003;41:659-60.

24. Caceres-Loriga FM, Perez-Lopez H, Santos-Garcia J, Morlans-Hernández K, Marrero-Mirayaga MA. Thrombolytic treatment as first option in recurrent tricuspid prosthetic valve thrombosis and Ebstein anomaly. J Pharm Sci. 2005; 8:332-4.

25. Voelkel NF, Quaife RA, Leinwand LA, Barst RJ, McGoon MD, Meldrum DR, et al. Right ventricular function and failure: report of a National Heart, Lung, and Blood Institute working group on cellular and molecular mechanisms of right heart failure. Circulation. 2006;114:1883-91. 